\title{
Literature Review of Water Alternation Gas Injection
}

\author{
Mohammed A Samba ${ }^{1}$, Mahmoud O. Elsharafi ${ }^{2}$. \\ ${ }^{1}$ Member of Petroleum Engineering Department, Sebha University, Libya \\ ${ }^{2}$ McCoy School of Engineering, Midwestern State University, Wichita Falls, TX 76308, USA
}

\begin{abstract}
The Water Alternating Gas (WAG) process is a cyclic method of injecting alternating cycles of gas followed by water and repeating this process over a number of cycles. The main purpose of WAG injection is to improve oil recovery, by increasing both of macroscopic and microscopic sweep efficiency and to help maintain the reservoir pressure. Also, WAG injection is to postpone the gas breakthrough. The WAG process provides mobility control in fast zones which extends gas project life and oil recovery.

This paper provided a comprehensive literature study about WAG injection. This paper has collected most of the requirements of the petroleum engineers that has to know about the WAG injection started from basic concepts until the design parameter for WAG injection.
\end{abstract}

Keywords: Enhanced oil recovery, WAG injection

Corresponding Author: moh.samba@sebhau.edu.ly

\section{INTRODUCTION}

Enhanced oil recovery (EOR) refers to any reservoir process used to change the existing rock/oil/brine interactions (fluid/fluid interaction; fluid/rock interaction) in the reservoir in order to increase the oil recovery, and this interaction might reduce the interfacial tension, oil swelling, reduce oil viscosity; also wetability modification (Don W. Green et al., 1998). The following flow sheet shows the types of various EOR methods that are currently employed in the oil industry.

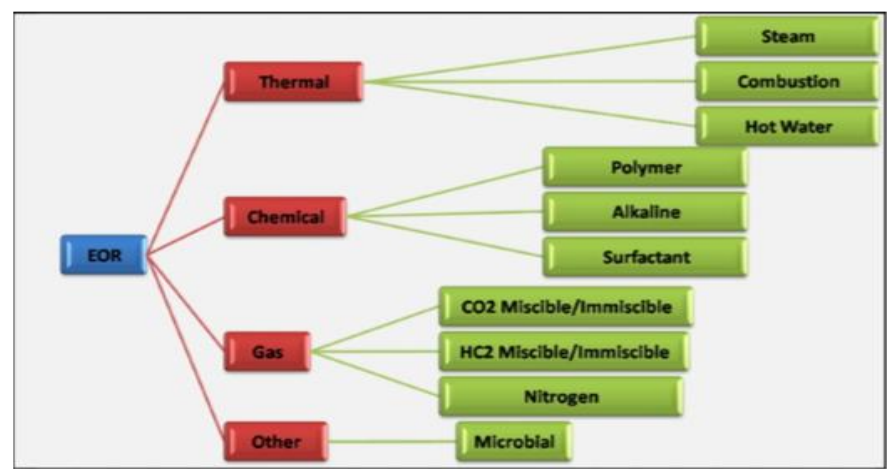

Figure 1 Flow Sheet for EOR Methods.

EOR has a lot of methods and every method has its own considerations to use it. One of into two types those methods is gas injection. Gas injection can be classified: continues gas injection (CGI) and water alternating gas injection (WAG) but this literature includes the second part WAG injection.

Recently, the WAG injection is widely uses because it has been compared with gas injection and water injection. It has proven more economically than both of them. WAG has been used in a deep reservoir, offshore, onshore and in a different rock type successfully (Christensen, et al., 2001).

\section{The Main Purpose of WAG Injection}

The main purpose of the miscible gas slugs is to increase the microscopic sweep efficiency, and contact attic oil in areas not contacted by water injection, in high permeable sandstone reservoirs gravity 
segregation is common. Gas will tend to migrate to the top of the reservoir and the more dense water will tend to migrate to the bottom of the reservoir, hence attic oil in the upper parts of the reservoir may be contacted by the injected gas, at the same time the water flood will play as a piston to push forward the miscible slug and that is will increase the microscopic efficiency because the unswept reservoir area will be smaller. Thus the residual oil to WAG is less than the residual oil for the water and the residual oil for gas $\left(S_{\text {orwag }}<S_{\text {orw }} ; S_{\text {org }}\right)$. A combination of the improved microscopic displacement efficiency of gas injected with the improved macroscopic displacement efficiency by water injection improved oil recovery can be achieved (Caudle, et al., 1957), (Suphattra, et al., 2011). Figure (2), (3), (4) shows how the WAG injection could sweep more area in the reservoir.

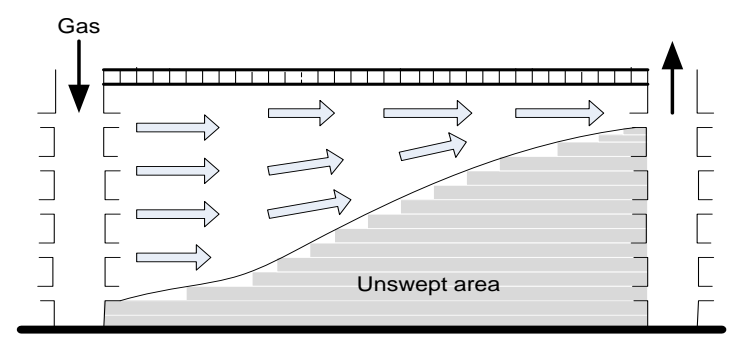

Figure 2 The gravity effect during the gas injection.

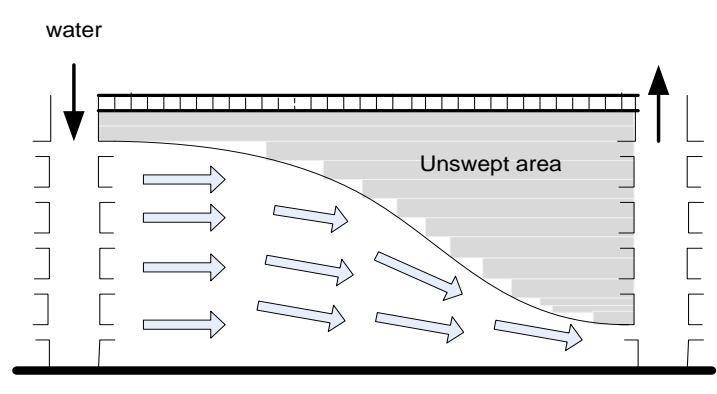

Figure 3 The gravity effect during the water injection.

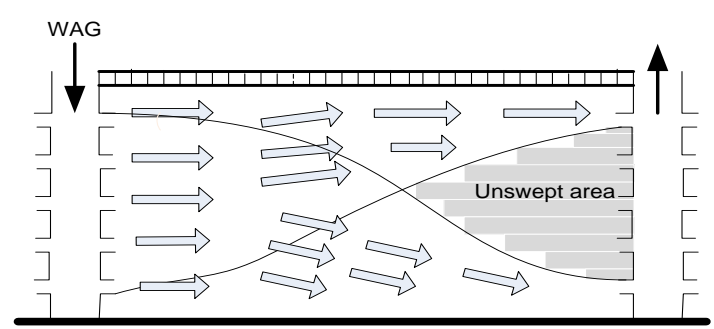

Figure 4 The gravity effect during the WAG injection.

\section{WAG PROCESS CLASSIFICATION}

The classification of WAG injection provide a deep understanding of the accurate design for WAG injection. Howevere, in general, WAG can be classified into six types depending on how they are used:

\section{a. Miscible WAG Injection}

It is difficult to distinguish between miscible and immiscible WAG injections. In many cases multicontact gas/oil miscibility may have been obtained, but much uncertainty remains about the actual displacement process. It has not been possible to isolate the degree of compositional effect on oil recovery by WAG injection. Miscible projects are mostly found onshore, the early cases used expensive solvents like propane, which seem to be a less economically favourable process at present. Most of the miscible projects reviewed are re pressurized in order to bring the reservoir pressure above the minimum miscibility pressure (MMP) of the fluids, because of failure to maintain sufficient pressure, meaning loss of miscibility, real field cases may oscillate between miscible and immiscible gas during the life of the oil production. Most miscible WAG injections have been performed in a close well spacing, but recently miscible processes have also been attempted even at offshore type well spacing (Christensen, et al., 2001).

\section{b. Simultaneous Injection of Water and Gas behind the Front}

This type of injection can be classified under the miscible WAG, firstly we have to inject the gas until it get miscible with oil and then we follow it by simultaneous water and gas in the same time, but it should be there is a gas band between the miscible zone and water edge and in the same time we have 
to consider the WAG ratio. WAG ratio should be calculated under consider the relative permeability curve for water and gas, this type does not include any economic factors just focus on how we can get the miscibility condition whatever the gas volume injected (Caudle, et al., 1957).

\section{c. Immiscible WAG Injection}

This type of WAG process has been applied with the aim of improving frontal stability or contacting unswept zones to get high sweep efficiency. Some applications have been in reservoirs where gravitystable gas injection cannot be applied because of the limited gas resources or reservoir properties, such as low dip or strong heterogeneity. In addition to sweep efficiency, the microscopic displacement efficiency may be improved. The residual oil saturations are generally lower for WAG injection than for a water flood and sometimes even lower than a gas flood, owing to the effect of three-phase and cycle dependent relative permeability.

Sometimes during the immiscible WAG injection the first gas slug dissolves to some degree into the oil. This can cause mass exchange (swelling and stripping) and a favorable change in the fluid viscosity/density relations at the displacement front, the displacement can then become near-miscible (Christensen, et al., 2001).

\section{d. Foam Assisted Water Alternating Gas (FAWAG) process}

FAWAG is usually introduced in reservoirs with WAG already in use. FAWAG can be intended to create a foam barrier that impedes the upward passage of the gas, forcing it spread laterally and in the process contact previously upswept parts (Saleem, Q, et al., 2012). This method is more effective when the vertical permeability so high, thus the foam it will make like barrier to prevent the gas segregation. Figure 5 shows how the FWAG can improve oil recovery factor.

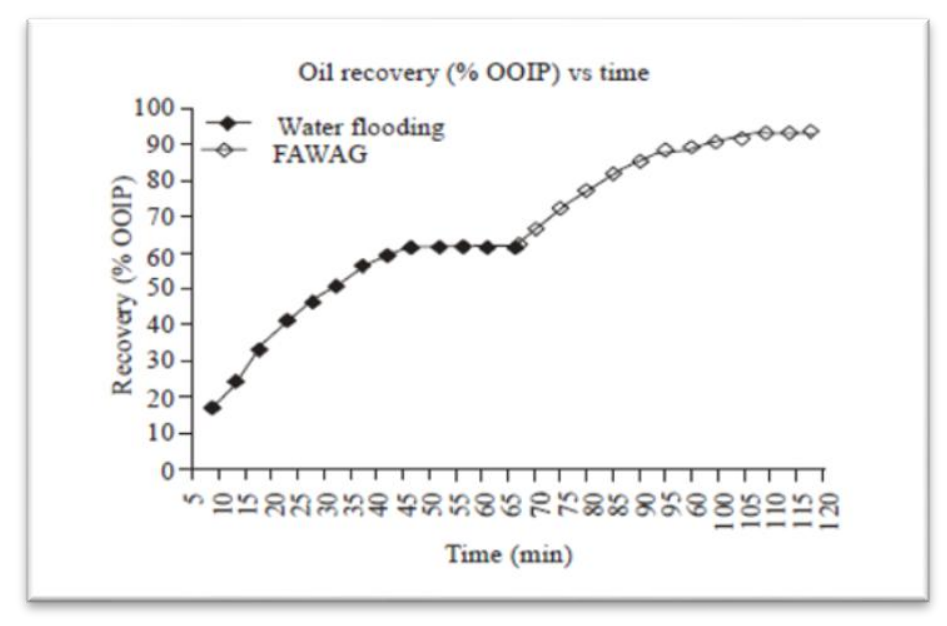

Figure 5 Oil recovery after FAWAG application after (Saleem, Q, et al., 2012).

\section{e. Chemically WAG Injection ( CWAG )}

Chemical Wag injection is a Chemical slug ( mixture of alkaline, surfactant and plymer) which will be injected during WAG process to reduce interfiail tension (IFT) and improve the mobility ratio. In a CWAG process, a chemical slug is a chases by water, preceded by gas slug and followed by alternate $\mathrm{CO}_{2}$ and water slug or chemical slug injects after one cycle of gas and water slug (Don W. Green et al., 1998).

\section{f. Hybrid WAG Injection}

When a large slug of gas is injected, followed by a number of small slugs of water and gas, the process is referred to as hybrid WAG injection. Other types based on injection pressures and method of injection. 


\section{Previous Studies about WAG Injection :}

A review of WAG field experience has been done in 2001, this review considered about 59 fields, started from the first reported WAG injection in 1957 in Canada with hydrocarbon miscible WAG to the new experience in the North Sea. Since the WAG has been applied to the most fields around the entire world and is going to increase as shown in the figure 6 (Christensen, et al., 2001).

The Performance of WAG in a Stratified Reservoir "Hassi-Messaoud Field; Algeria" has been presented in 2004, the objective of this study is to improve the sweep efficiency by calculating the optimum WAG parameters (WAG ratio, WAG cycle, etc.). After they have run a sensitivity analysis with variant WAG ratio and WAG cycle, the study obtained the optimum WAG ratio 2 and WAG cycle (1 year) (Nabil, et al., 2004).

A case study has been done in the Hassi Massaoud field-Algeria, With most than 40 years of miscible gas injection history, the necessary gas injection volume is increasing year after year according to the development plan of the field. In order to reduce gas injection volume need of gas volume and increase the recovery, a WAG Pilot was implemented in the field in 2006 with full package of measurements to understand the behavior of the fluids in the Hassi Massaoud field with a reservoir describes like very heterogeneous (Belkacem, et al., 2004).

Water Alternating Gas Injection for Enhanced Oil Recovery in the Phitsanulok Basin has been done in 2011. The WAG has been applied in this field for two reasons, the first reason, because the water flood has been applied successfully since 1980, the second reason because there is enough gas available in this basin. The objective of this study is to determine the appropriate operational program of the study field and to estimate the recovery efficiency of the WAG method by using the reservoir simulation eclipse-300 (Suphattra, et al., 2011).

Improving Miscible Displacement by Gas Water Injection has been presented in 1957, the objective of this study is to find a way to increase the sweep efficiency during miscible displacement process, and compare the results with conventional method. The results of this study, state that there is one way to increase the sweep efficiency by decreasing the mobility behind the front. It also obtained that the simultaneous injection of gas and water behind the miscible displacement will reduce the relative permeability to gas and lower total mobility ratio, where the gas zone should be exists between miscible slug and the edge of the water. Comparative study has proven that the simultaneous WAG gave $90 \%$ of sweep efficiency, while the continues gas injection gave $60 \%$ of sweep efficiency (Caudle, et al., 1957).

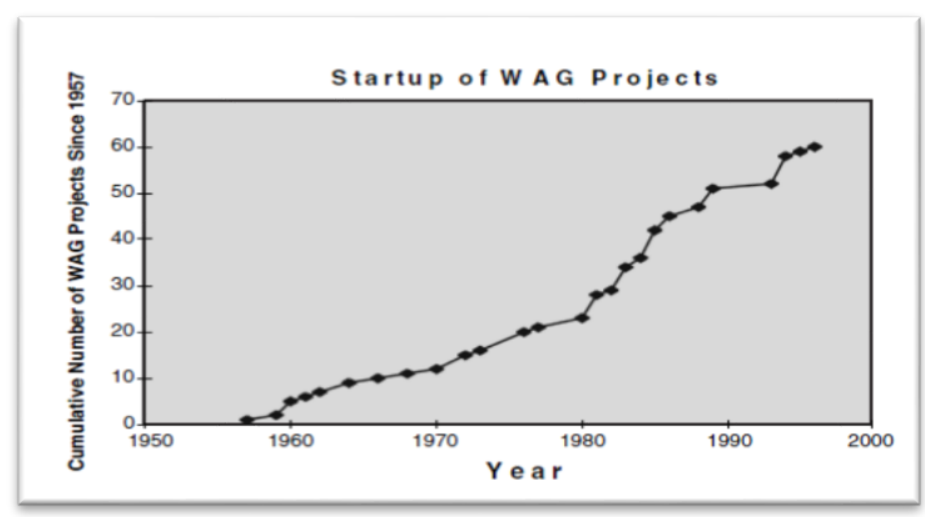

Figure 6 Cumulative number of worldwide WAG application from the first project in 1957 to 1996 (Christensen, et al., 2001).

\section{MOBILITY CONTROL PROCESS}

The mobility ratio controls the areal sweep efficiency in the reservoir and the vertical sweep efficiency is controlled by the difference in the density of the injected and displacing fluids (Don W. Green et al., 1998).. As have mentioned the low residual oil saturation in the swept zones, overall poor volumetric reservoir sweep and early break through are the main concerns in gas field. The unfavorable mobility 
ratio in gas floods being the main cause. Flood profile control in gas fields is instrumental for a successful project (Caudle, et al., 1957).

Most of the researches going to improve the flood profile during gas fields. These include the direct thickeners with gas soluble chemical like Telechelic Disulfate, Polyflouroacrylate and FlouroacrylateStyrene copolymers, which can increase the viscosity of gases several folds (e.g. For $\mathrm{CO}_{2}$ viscosity increase from $2-100$ fold). Other methods such as, modifications in the injected slug such as the use of Natural Gas Liquids (NGL) instead of water for highly viscous oils in low pressure, poorly producing and unconsolidated formations are also proposed, most of those studies are still inception or experimental stage and until now have not except as a part of the current commercial flooding technology (Moritis, G, 1995).

The mobility ratio should be $\leq 1$, usually denoted as favorable mobility ratio. While if the $M>1$ then it means unfavorable displacement, where the mobility ratio equal:

$M=\frac{\text { displacing mobility }}{\text { displaced mobility }}$

$\mathrm{M}=\frac{\mathrm{k}_{\mathrm{rd}} / \mu_{\mathrm{d}}}{\mathrm{k}_{\mathrm{ro}} / \mu_{\mathrm{o}}}$

\section{Where}

$\mathrm{k}_{\mathrm{rd}}=$ Relative permeability of displacing fluid

$\mathrm{k}_{\mathrm{ro}}=$ Relative permeability of displaced fluid.

$\mu_{\mathrm{d}}=$ viscosity of the displacing fluid.

$\mu_{\mathrm{o}}=$ viscosity of the displaced fluid.

Based on previous equation, the mobility ratio should be less than 1 to prevent the early break through (improve macroscopic efficiency). But in this formula calculate only the mobility ratio by consider the relative permeability and viscosity of displacing and displaced fluid. There are another factor that effect on mobility ratio like the different permeability between the reservoir layer, porosity, area, etc. But in the some fields the mobility ratio depends that velocity of displaced fluid should be equal or smaller than the velocity of displaced fluid $\left(\mathrm{v}_{\mathrm{w}} \leq \mathrm{v}_{\mathrm{o}}\right)$ and in this case it should be calculate the both of velocities by use Darcy law and this way is more accurate to calculate the mobility ratio. Additionally, we have to consider the geological factor that may lead to unexpected passing of fluid because the channelling in the high permeability zone or fracture.

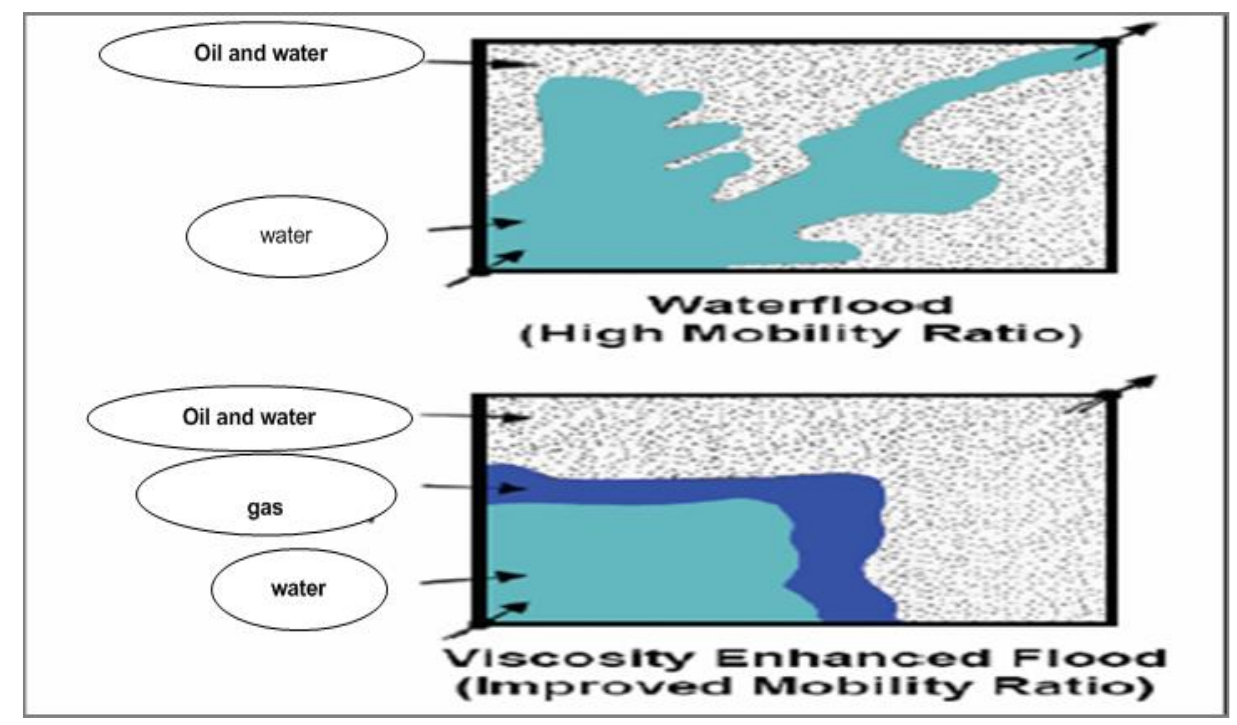

Figure 7 Mobility control process during WAG injection . 


\section{WAG PROCESS}

The WAG process today is most commonly employed around the entire world. In recent years there has been an increasing interest in water alternating- gas (WAG) processes, both miscible and immiscible. We can notice that almost all the commercial miscible gases today employ the WAG method to use different types of gases such as Phitsanulok basin (Suphattra, et al., 2011). The better type of gases used for the miscible displacement is the $\mathrm{CO}_{2}$, because when miscible $\mathrm{CO}_{2}$ applied, the required injection pressure less than when use another gas injection. Also the gas injection has higher microscopic displacement efficiency than the water injection efficiency as have explained due to low interfacial tension between oil and gas phase.

Figure 8 shown the WAG process. It should ensure the miscible slug size be enough to create the miscibility, in the same time the miscible slug size will not disappear before the miscible slug has arrived to the producing wells, and ensure the following fluids will not breakthrough the miscible zone otherwise loss the miscibility will happen.After injected the miscible zone, gas and water injected respectively, where the period between the gas injection and water flood it call WAG cycle. The ratio of the volume of gas injected to the volume of water injected it calls the WAG ratio. Those factors play important factors during WAG design especially to improve the economic side of projects.

As we have mentioned the using of WAG process is increasing and recently some oil recovery methods use the proper produced gaseous hydrocarbon as injection fluid. This is an interesting alternative for offshore operations due to the limitations of gas available, storage and exportation. This option is mainly attractive if the offshore field produces (Suphattra, et al., 2011).

About $40 \%$ of projects in United State are $\mathrm{CO}_{2}$ injection, most of them are WAG and almost of those projects about $80 \%$ of WAG in US reported in economic success. The WAG has been applied to different types of reservoir, immiscible and miscible projects (process type), also included percentage of rock type that has applied by WAG, onshore and offshore WAG, and at last the different types of the gas injection as shown in figure 10 (Christensen, et al., 2001).

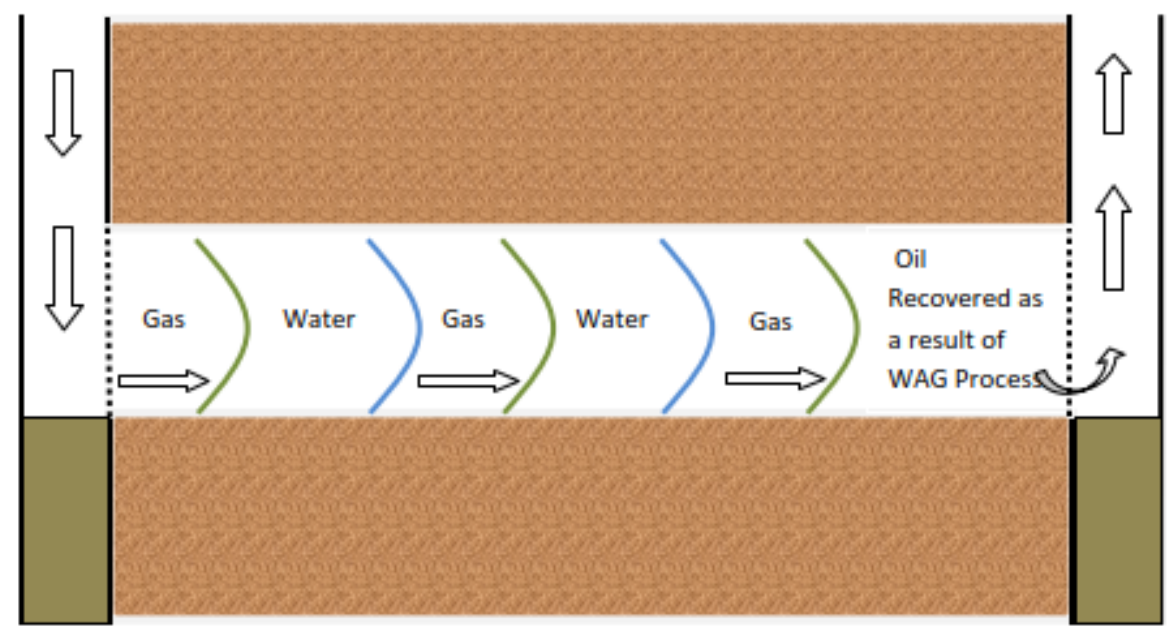

Figure 8 WAG process (Zahoor, et al., 2011). 


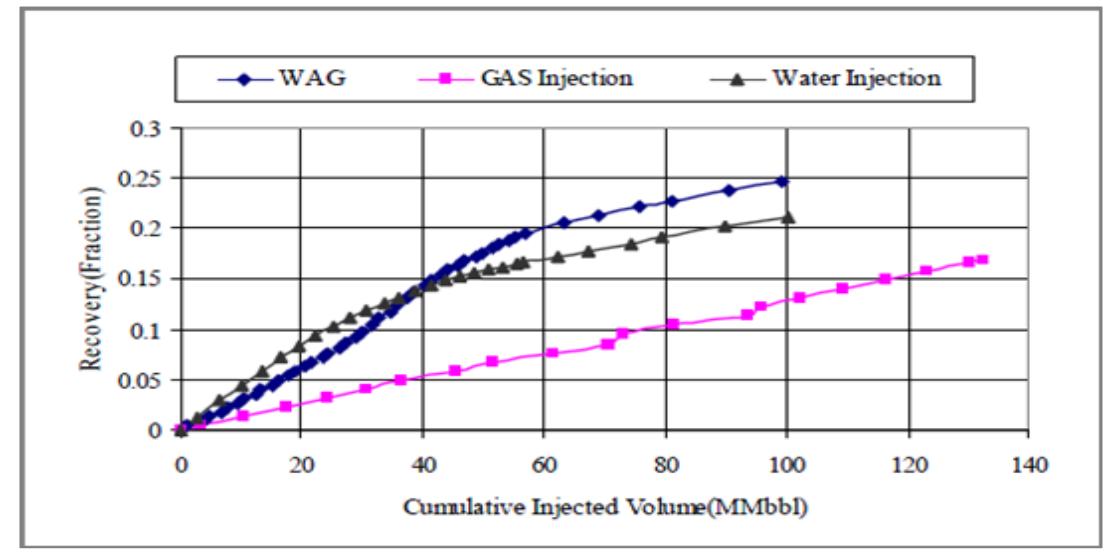

Figure 9 Compare study for WAG and conventional method (Nabil, et al., 2004).

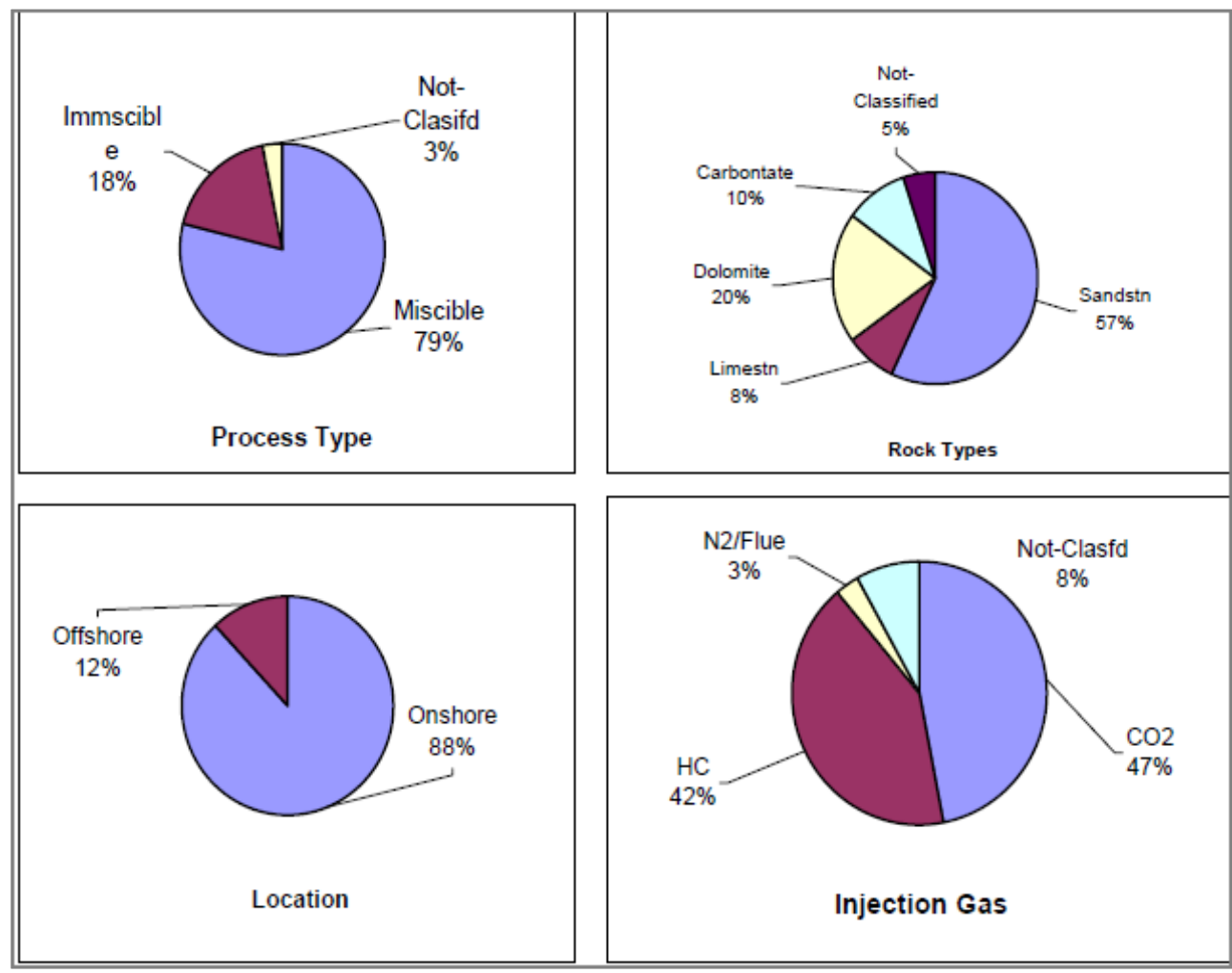

Figure 10 WAG survey - Distribution / Application of WAG (Christensen, et al., 2001).

\section{PROBLEMS ASSOCIATED WITH THE WAG PROCESS}

The water-alternating-gas process (WAG) was originally proposed to improve sweep efficiency during gas injection and it combines the advantages of water flooding give better microscopic displacement efficiency and improved macroscopic but during the production some operation problems are very difficult to avoided because the alternative between the gas and water, otherwise cause a lots of problem more than continues gas injection, the most popular problems during the WAG fields are:

\section{a) Early Breakthrough in Production Wells}

Early gas breakthrough is a common occurrence especial in gas cycling operations, or in nitrogen floods in gas condensate reservoirs. This is often due to nitrogen or dry gas migration through thief zones or natural fractures. Actually during the gas injection the relative permeability of the gas is high because that it give high mobility ratio for the gas injection, while during the WAG injection, the water will fill 
some pores, thus the relative permeability of gas will decrease due to the decrease the effective permeability, then the mobility ratio will decrease (Nabil, et al., 2004).

The mobility ratio plays an important factor to control the break through, early breakthrough mostly occur when poor understanding of the reservoir heterogeneity happened. This problem is very critical to solve it. There are some fields reported that they closed their wells for long time before the schedule due to the early breakthrough, this will causes the loss of the pressure; loss of miscibility, it will result low recovery factor (Christensen, et al., 2001). To avoid the early break through does not depend only on the injecting fluid, also depends on reservoir heterogeneity and perforation set. Vertical cross flow has the significant effect on the break through, where it depends on fluid density difference, actual flow velocity, and ratio of vertical to horizontal permeability. During the WAG the water will follow after the gas, the alternate between the gas and the water will help to delay the break through (L.G. Jones, et al., 1989).

\section{b) Reduced Injectivity}

Loss of injectivity and/or failure of pressure maintenance in the actual reservoir, attributable to many factors, cause the process to fluctuate between miscible and immiscible during the life of the process. Less the injectivity mean less the injecting fluids (gas or water), this it will cause the loss of miscibility (drop the reservoir pressure). The cause for reduced injectivity could be a change in relative permeability owing to three-phase flow (Christensen, et al., 2001). Reduce the injectivity may cause decreased the production rate correspondingly due to the decreased injectivity, also can be result of redistribution of pressure profile when the injection is change from the gas to water and vertical permeability is limited (Nabil, et al., 2004).

The residual $\mathrm{CO}_{2}$ saturation is suspected to be a significant factor for reducing injectivity during WAG processes for $\mathrm{CO}_{2}$ EOR projects. There is increasing interest in minimizing $\mathrm{CO}_{2}$ (greenhouse gas) emissions by sequestrating $\mathrm{CO}_{2}$ in depleted oil and gas reservoirs or in saline aquifers. The interest in increasing $\mathrm{CO}_{2}$ injection into geological formations requires a better understanding of mechanisms and extent of $\mathrm{CO}_{2}$ plume development and subsequent dissolution into formation brine (Reid, et al.,2007).

The residual $\mathrm{CO}_{2}$ consider one of the main factors that cause reduced the injectivity, during the WAG the loss of injectivity commonly occurs through the change between the displacing fluids (gas and water) except the simultaneous WAG injection, but we can control this by run sensitivity of WAG ratio and WAG cycle, also pattern injection strategy play an important factor to avoid reduced the injectivity especially when the distance between the well locations is not far. The injection rate and WAG ratio could control the water and gas injectivity into low and high permeability layers. The injectivity into each layer depends on the WAG ratio and the volume of fluid injected in each cycle.

\section{c) Corrosion}

The breaking down or destruction of a material, especially a metal through chemical reactions. The most common form of corrosion is rusting, which occurs when iron combines with oxygen and water.

$\mathrm{CO}_{2}$ is a corrosive material when combined with water, there was uncertainty regarding the severity of corrosion. Experience indicates that corrosion has not been a severe problem mainly because of the preventative measures taken by industry. Methods to reduce corrosion include the use of corrosion inhibitors, and fiber glass gathering systems. The problem focus when we use the facilities of the secondary recovery during the tertiary period and those facilities designed for the secondary recovery.

The mechanism for this problem that the small hole formed on the surface of steel, as a result of the collision between the small sands that associated with the production fluids and surface of steel then after provide the suitable condition it will form corrosion.

They were some fields have been reported corrosion problems during WAG injection, those problems seem to occur mainly on the injection side, and in two cases (Wertz Tensleep and Purdy Springer) the submersible pumps were affected. These problems have been solved, in most cases, by usage of high quality steel (different kinds of stainless steels or ferric steel), coating of pipes, and treatment of equipment (Christensen, et al., 2001). 


\section{d) Scale Formation}

Scale formation is a major problem in the oil industry. They may occur in down hole or in surface facilities. The formations of these scales plug production lines and equipment and impair fluid flow. Their consequence could be production equipment failure, emergency shutdown, increased maintenance cost, and an overall decrease in production efficiency. This problem is always happen when we produce through the casing. The formation stress will effect on the pipes as results as of failure the pipe lines, sometimes it will damage the coated with an extra layer for corrosion protection, otherwise it will stop the production and it will need either for chemical squeeze treatments or repairing the damage.

\section{e) Different Temperatures of Injected Phases}

In the WAG injection, inject the gas and the water from the same wells, the gas and water have different temperature, due to the different temperature between the water and the gas, the pipe will exposed to the different temperatures (Expansion and contraction) related tubing failures. This problem has been reported in the Brage case, further adjustment of the possibility for tubing expansion eliminated this problem in other WAG injectors. Quarantine Bay34 $\left(\mathrm{CO}_{2}\right.$ injection) is another example of adjusting the injection design to successfully prevent this problems. In modern studies equipped this problem to create the steam assisted WAG (Christensen, et al., 2001).

\section{DESIGN PARAMETERS FOR THE WAG PROCESS}

It is very important to understand the design parameters for WAG injection, because we have to know the effects of each parameter, that is will feed us by more understanding for WAG mechanism. The most important parameters for WAG design are the reservoir characteristics and heterogeneity, rock and fluid characteristics, composition of injection gas, injection pattern, WAG ratio, relative permeability effects and flow dispersion etc.

\section{Reservoir Heterogeneity and Stratification}

Reservoir heterogeneity controls the injection and sweep patterns in the flood. All studies that have been reported about reservoir heterogeneity and stratification indicate that the reservoir heterogeneity has a strong influence on the oil recovery process. The horizontal fluid flow in the vertical communication porous strata is influenced by flow perpendicular to the bulk flow caused by viscous forces, capillary forces, gravity and depression (Rogers, et al., 2000). Cross-flow may influence to increase the vertical sweep, but generally the effects are detrimental to oil recovery - mainly due to the gravity segregation and decreased flow velocity in the reservoir. This leads to reduced frontal Advancement in lower permeability layer. WAG injection and continuous gas injection are more strongly affected by these phenomena.

Additionally, understanding the heterogeneity stratification is very important, otherwise will understand the fluid injection behaviour, a lot of reservoirs have reported problems because of misunderstanding of the heterogeneous stratification of the reservoir. The most common problems such as loss of miscibility, channelling during the injection.

They are two methods to calculate the heterogeneous of formation, the first method is Stiles's method, the properties of this method are identical except the absolute permeability. Also, it is used only for linear flow and limited range of mobility ratio. The second method to calculate the heterogeneous formation is Dekstra - Parsons Method, the main advantage of this method is a wide range of mobility ratio (M), also it can be used for radial flow and it is an easy and quick method to give qualitative values for the recovery factor for projects.

However, the effects of reservoir specific and the overall effect are dependent on various parameters such as permeability, porosity, reservoir pressure, capillary pressure and mobility ratio. We have to understand the real concept for heterogeneity and stratification of the reservoir to ensure the success of the project. 


\section{Rock and Fluid Characteristics}

Christensen, et al., 2001 have shown the successful miscible displacements application for WAG for various types of reservoir with different types of rocks such carbonate, limestone, dolomite and sandstone reservoirs. All of those types of rock applied with different types of gases such as hydrocarbon and non hydrocarbon gases as injection fluids.

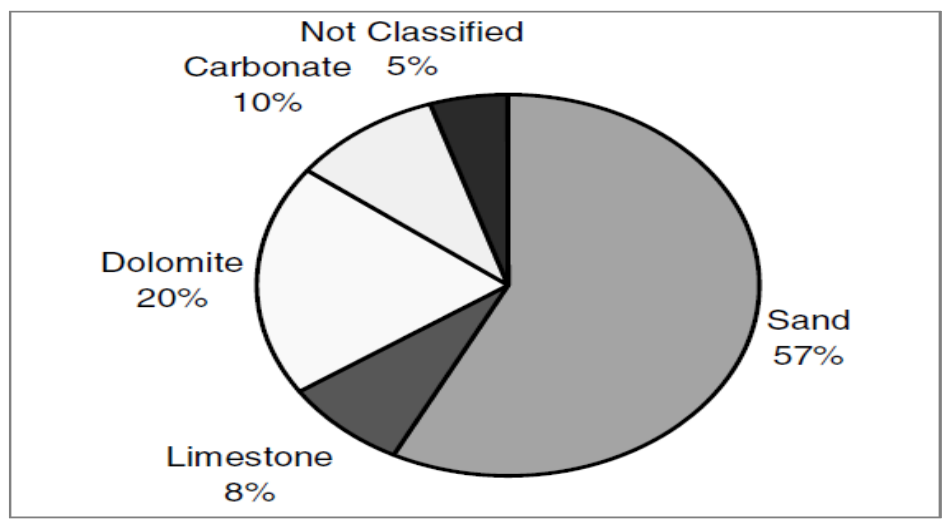

Figure 11 Rock types where WAG injection has been applied (total of 59 projects) (Christensen, et al., 2001).

\section{Injection Gas Characteristics}

Injection gas characteristics are more important for WAG projects, the injection gases are used for WAG can be classified into three groups: $\mathrm{CO}_{2}$, hydrocarbons, and non hydrocarbons $\left(\mathrm{CO}_{2}\right.$ excluded). Choosing the type of gas injection depends on the location of the field where it depends on the availability of gas in the field. At Phitsanulok basin they applied WAG injection because there is enough gas in the field whatever this type of gas (Suphattra, et al., 2011). There is a good example of this issue at Ekofisk field where miscible hydrocarbon WAG was suggested to be suitable for Ekofisk, even though $\mathrm{CO}_{2}$ WAG yielded higher incremental production under laboratory conditions, but $\mathrm{CO}_{2}$ is not available in Ekofisk field because that they used hydrocarbon WAG for this field. The entire offshore fields use hydrocarbon WAG, however the option to use $\mathrm{CO}_{2}$ is being tested for environmental concerns (Christensen, et al., 2001). Figure 12 shows the types of injection gas used for WAG applications.

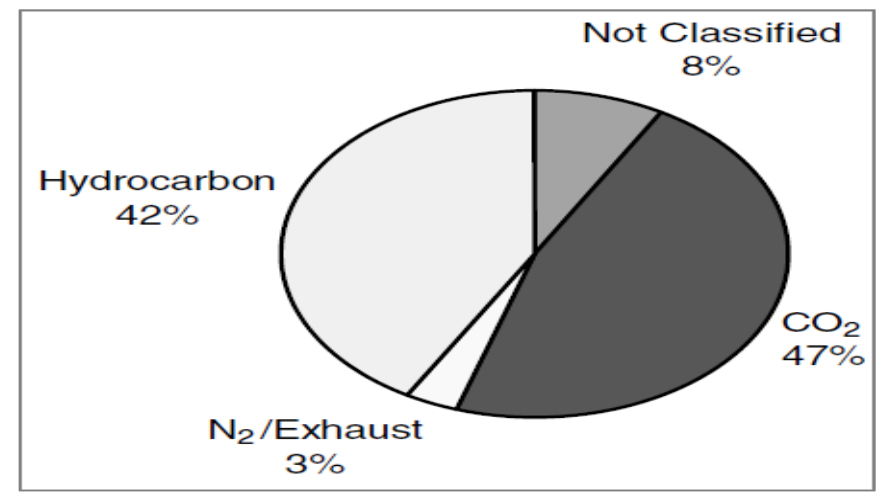

Figure 12 Types of injection gas used in WAG applications (total of 59 projects) (Christensen, et al., 2001).

\section{Injection Pattern}

Pattern flooding is principally employed in reservoir in order to ensure a uniform sweep, the injection wells are distributed among the production wells into injectors or by drilling infill injection wells.

The WAG has been applied for different types of injection pattern, where the five spot most popular for the most fields that have been reviewed, even it give high cost since it gives the best control over the process. This review reported about 9-spot pattern in miscible WAG and hybrid WAG (Christensen, et al., 2001). 
Actually to choose of the injection pattern depends on reservoir geology and reservoir type, also the volume of the reservoir rock (oil bearing), to be swept. The problem is recently most of the fields they do not do plan of development of the filed in initial life of the field, actually we can control the injection pattern just if we did plan of development in the early time before the random drilling happened. Thus, it will be very difficult to choose the proper injection pattern due to the randome drilling.

\section{Tapering}

Tapering is decreasing the amount of the gas to water ratio, tapering apply to control the gas mobility and avoid override phenomena to avoid the early break through, also applied for economic purpose. Tapering is especially important when an expensive gas source is used.

\section{WAG Ratio}

It is the volume of injected gas divided by the volume of the injected water at reservoir condition in each cycle. The WAG ratio design depends on the mobility consideration and also economic considerations, we can see in figure 13 the WAG ratio has a significant effect on the EOR. In this case were run to test for sensitivity the number and the duration of alternating cycles (WAG ratio), the recovery factor decreases as the WAG ratio decreases.

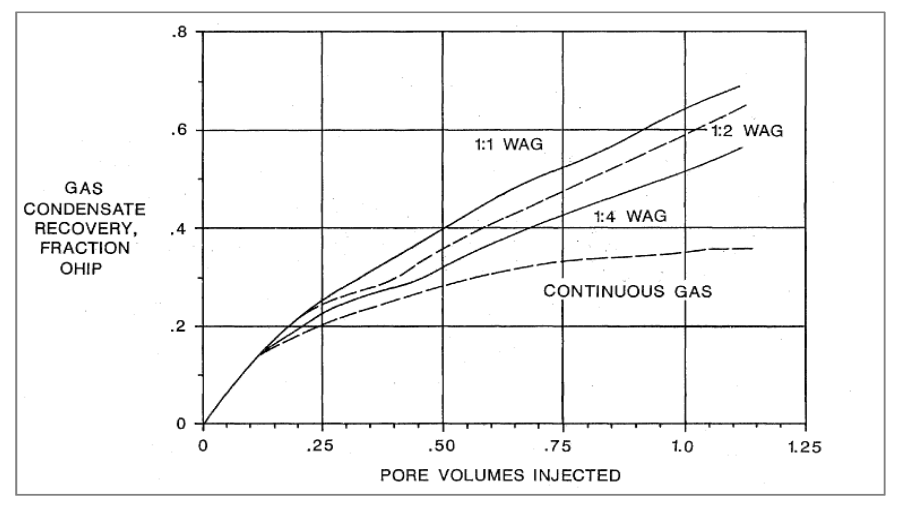

Figure 13 Effect of WAG ratio on oil recovery (L.G. Jones, et al., 1989).

During the WAG projects we have to run a sensitive analysis for WAG ratio and see how it is effecting on our field and obtain the economic volume for gas injection, at the same time consider the highest recovery factor. Christensen, et al., 2001 indicated that the most popular WAG ratio is 1:1, this ratio has been applied for the most fields, that it does not mean that WAG ratio 1:1 will give us higher recovery, the decision to take the optimum WAG ratio it depends on the gas availability and reservoir heterogeneity, also it should be consider the economic side to inject high gas volume.

\section{Flow Dispersion Effects}

Dispersed flow is characterized by the flow where one phase is dispersed in the other continuous phase. This flow configuration is observed in all types (gas-liquid, gas-solid, liquid-liquid and liquid-solid) of two-phase flows. There are a lot of factors that effect on the flow dispersion during the displacement such as heterogeneity, permeability, etc.

During the simulation the pseudo relative permeability curves control numerical dispersion by accounting for the difference in block sizes between the fine grid and the model grid. The WAG injection results in a complex saturation pattern as both gas and water saturations increase and decrease alternatively. This results in special demands for the relative permeability description for the three phases (oil, gas and water). The effect of the unstable frontal advance during the displacement that might cause the dispersion.

A successful miscible-flood simulator should allow for the possibility of unstable frontal advance and must describe the dispersion phenomenon, special that related to the determination of effective fluid properties (Caudle, et al., 1957). 


\section{Gravity Considerations in WAG}

It is recognized the gravity plays an important role in all reservoirs especially in the thicker reservoir. A few computer runs indicated that gravity effects can be significant if the viscous forces are not sufficient to overcome gravity forces. The effect on production and sweep due to gravity was sensitive to injection rate and the ratio of the thief zone to matrix permeabilities (L.G. Jones, et al., 1989). WAG flooding is often limited by the gravity segregation, which causes the injection of the gas to rise to up of the formation and water to the bottom as shown in figure 2, 3 and 4 .

The stability of the WAG front based on the travelling-wave solution concept, often referred to as gravity-stable displacement. The travelling-wave solution corresponds to a balance of the effects of gravity and heterogeneity, resulting in a uniform velocity of the displacement front in a cross section and hence to a high vertical sweep efficiency. This is in contrast to the general situation where the displacement front moves faster in highly permeable zones (viscous tonguing) or in gas and water gravity tongues (George, 1994).

The Gravity-segregated multiphase flow takes place in reservoirs with high vertical permeability and large distances between wells, a situation relevant for many North Sea reservoirs. The gravity estimates the gravity segregation and hence controls the sweep efficiency. Although the purpose of WAG injection is to mitigate the gravity segregation effects and provides a stable injection profile, WAG in down dip reservoirs proved better profile control and higher recoveries for a lot of projects. Hence the gravity considerations in WAG design are indispensable.

\section{Laboratory Studies and Simulation}

The laboratory studies are very important for successful WAG flooding where laboratory studies underway, opening a new window of opportunities for EOR methods. The absence of reliable data leads to an inadequate understanding of reservoir behaviour and consequently to poor predictions (Blunt, MJ. et al, 1994). The laboratory studies consider one of the most important factors to choose the type of EOR methods that will be success in the field.

The slim tube tests, PVT data, swelling tests and tertiary core floods, all of those tests doing through laboratory studies (George, 1994), all of those tests are very important during the miscible WAG injection. There are another process depends on the laboratory tests such as simulation process, the simulation is an attempt to model a real-life or hypothetical situation on a computer so that it can be studied to see how the system works. By changing variables in the simulation, predictions may be made about the behaviour of the system. It is a tool to virtually investigate the behaviour of the system under study.

The laboratory studies should be very accurate to ensure getting the accurate results during the simulation. The results of the simulation depend on the accuracy of the Laboratory results. The quality of data to the simulator is the key to provide the quality results of predictions.

\section{Effect of Brine Composition}

During the injection there are small solid material (fines) it will migration, since some time they recognized those fines have affect on the recovery factor, it will effect on the flow behavior (relative permeability) of the reservoir rock. The migration of the fines occurs because the motion of the fluid through the pore of the rock where some rock will loss it compaction and it will go to fragmentation. Laboratory studies have shown that brine salinity, composition and $\mathrm{pH}$ can have a large effect on the microscopic displacement efficiency of oil recovery by water flooding and imbibitions (Eng, $\mathrm{J} \mathrm{H}$, Bennion, et al., 1993).

\section{CONCLUSION}

An extensive review of the WAG injection process has been presented. This study will introduce all the requirements information about the WAG injection. 


\section{REFERENCES}

Belkacem, et al., (26-28 June 2007 ) Miscible WAG Pilot - Hassi Messaoud field Field, Algeria IFP OAPEC Joint Seminar "Improved Oil Recovery (IOR) Techniques and Their Role In Boosting The Recovery Factor" Rueil-Malmaison, France.

Blunt, MJ. et al, (Feb. 1994) : "A Predictive Theory for Viscous Fingering in Compositional Displacement" SPERE 73.

CAUDLE et al., (Oct. 6-9, 1957) Improving Miscible Displacement by Gas-Water Injection, SPE 911, G Original manuscript received in Society of Petroleum Engineers office July 16, 1957. Revised manuscript received Sept. 17, 1958. Paper presented at 32nd Annual FalI Meeting of Society of Petroleum Engineers in Dallas, Tex.

Christensen, J R, Stenby, E H, Skauge , A, (January 2001) "Review of the WAG field experience", SPE 71203, revised paper 39883, presented at the 1998 SPE International petroleum Conference and exhibition of Mexico, Villhermosa, March 3-5, 1998. Paper peer approved 22.

Don W. Green, G. Paul Willhite, (1998) Enhanced Oil Recovery Henry L. Doherty Memorial Fund of AIME, Society of Petroleum Engineers.

Eng, J H, Bennion, D B, Strong, J B, (Oct 1993) Velocity Profiles in perforated completions, Journal of Canadian Petroleum Technology, Vol. 32, No. 8, pp. 49 - 54.

George A, Virnovsky,( 1994) Stability of Displacement Fronts in WAG Operations ,SPE 28622 ,first presented at the SPE Annual Technical Conference and Exhibition, held in New Orleans, LA, U.S.A.

L.G. Jones, A.S. Cullick, and M.F. Cohen, Mobil R\&D Corp. (1989) WAG Process Promises Improved Recovery in Cycling Gas Condensate Reservoirs, SPE 19113 this paper was prepared for presentation at the SPE Gas Technology Symposium held in Dallas, Texas.

Moritis, G, (1995), Impact of production and development RD\&D ranked", Production Editor, Oil and Gas Journal.Vol 93, Issue 44.

Suphattra et al.(2011), Water Alternating Gas Injection for Enhanced Oil Recovery in The Phitsanulok Basin.

Nabil, et al., (2004) The Performance of WAG in a Stratified Reservoir, Hassi-Messaoud Field, Algeria , SPE 88482 , This paper was prepared for presentation at the SPE Asia Pacific Oil and Gas Conference and Exhibition held in Perth, Australia.

Reid B. Grigg and Robert K. Svec (2007), $\mathrm{CO}_{2}$ Retention and Injectivity, Sixth Annual Conference on Carbon Capture and Sequestration - DOE/NETL.

Rogers, J D, Grigg, R B, (2000) A literature analysis of the WAG injectivity abnormalities in the CO2 process , SPE 59329, presented at the 2000 review SPE/DOE Improved Oil Recovery symposium on held in Tulsa, OK.

Saleem Qadir Tunio and Tariq Ali Chandio,(2002), Recovery Enhancement with Application of FAWAG for a Malaysian Field ,Published: Faculty of Geoscience and Petroleum Engineering, Universiti Teknologi PETRONAS, Malaysia.

Todd, M.R. and Longstaff, WJ, (1972), The Development, Testing and Application of a Numerical Simulator for Predicting Miscible Flood Performance," JPT 874; Trans., AIME, 253.

Zahoor, M.K ; Derahman, M.N; Yunan, (2011), WAG process design - an Updated Review. Barazilain jornal of petroleum and gas. 